\title{
Discussion on Tourism Industry Trend under Routine Prevention and Control of Epidemic
}

\author{
Pei $\mathrm{Li}^{1, *}$ \\ ${ }^{1}$ School of Tourism, Northwest Normal University, Lanzhou City, Gansu Province, China
}

\begin{abstract}
The tourism industry is still in the recovery period after experiencing the suspension caused by the COVID-19 epidemic. At present, it seems that the epidemic prevention and control has become a routine job, in this context, some changes and new trends are taking place to the tourism industry. This paper analyzes the data based on the tourism market and discusses the major trends in the development of the tourism industry. The analysis reveals that the consumer appetite to travel was not blunted by COVID-19 even if many countries and regions are currently closed for tourists. Health and safety continue to be main concerns of tourists during their travels. In addition, there is a growing tendency toward industrial integration as the tourism demand is becoming increasingly diversified and personalized. Another definite trend in the tourism industry is the digitalization construction in tourist destinations. It is certain that the digital technology will provide travel businesses with more possibilities, and the tourism industry, guided by the innovation-driven development strategy, will have a promising future.
\end{abstract}

\section{Introduction}

It could be said that the COVID-19 epidemic defined the world of 2020. The global public health crisis has brought profound influence on many human fields, such as social governance, economic patterns, development concept and lifestyle. The tourism industry was hit hard by the lockdown, isolation and other anti-epidemic measures across the world. In 2021, with the appearance of new variation strains, repeated epidemic situations in some areas as well as vaccination, the fight against the epidemic has become our new routine. As Zurab. Pololikashvili, the Secretary General of the UNWTO pointed out, the crisis is far from over although many countries have taken measures to ensure the safety of international travel. The epidemic in China has been, to a great extent, controlled thanks to the effective crisis management mechanism of the government and the cooperation of the public. In such a background, Chinese domestic tourism market shows a strong trend of recovery and some new features.

\section{Orderly recovery of domestic tourism market}

The whole tourism market of 2020 was shocked by the COVID-19 epidemic. The inbound and outbound tourism market has nearly come to a state of complete standstill. The domestic tourism market suffered great losses with 2.879 billion domestic trips, down by $52.1 \%$ from 2019, and with the total tourism revenue of 2.23 trillion Yuan, down by $61.1 \%$ from 2019 , as below in Fig. 1[1].

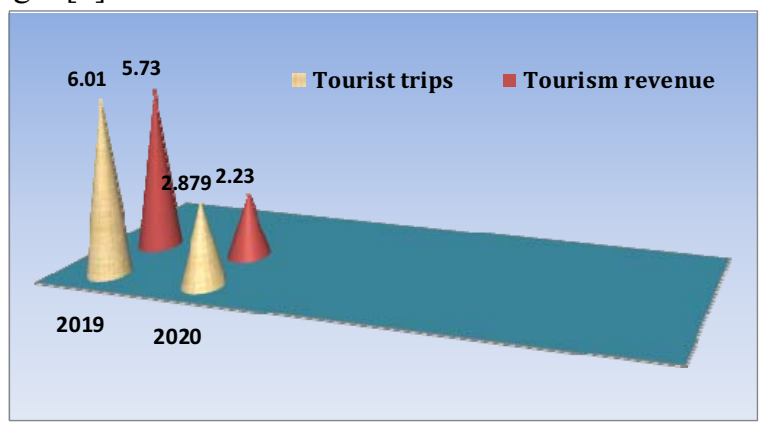

Fig. 1. Contrast between Domestic Tourism Market of 2019 and 2020

We could learn about from the data that 2019 was the most difficult year for the tourism industry since China has carried out the policy of reforming and opening-up. As the epidemic situation in China took a turn for the better, Chinese urban and rural residents calmed down from the early panic and gradually resumed normal leisure activities, which signals the recovery of Chinese domestic tourism market.

\subsection{Narrowed decline and increased recovery}

As shown in Fig.2[2], the tourism market fell by $83.4 \%$ in the first quarter, $-51.0 \%$ in the second quarter, $-34.3 \%$ in the third quarter and $-32 \%$ in the fourth quarter. We could conclude from the data that the decline narrowed gradually quarter by quarter. At the same time, the domestic travel market showed a trend of growing

\footnotetext{
*Corresponding author: peili919@163.com
} 
recovery during the public holidays in 2020. Let's take a look at the main indicators: the tourist trips and the tourism revenue. They recovered by $31.6 \%$ and $19.3 \%$ respectively from 2019 during the Tomb-sweeping Day holiday, recovered by $53.5 \%$ and $36.7 \%$ during the Labor Day holiday, recovered by $50.9 \%$ and $31.2 \%$ during the Dragon Boat Festival holiday, and recovered by $79.0 \%$ and $69.9 \%$ during the National Day holiday. They are presented as follows in Fig.3[3].

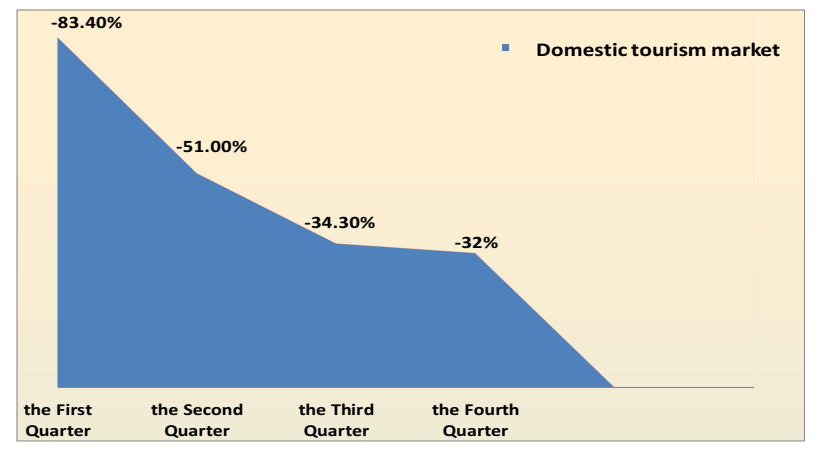

Fig. 2. Decline of Domestic Tourism Market in 2020

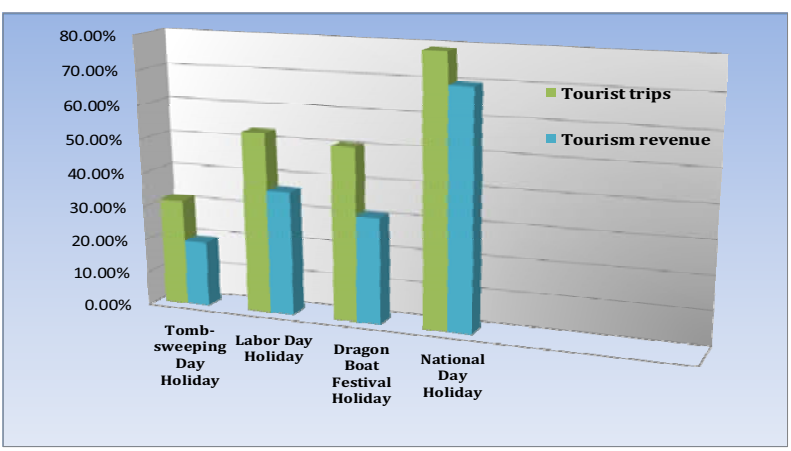

Fig.3. Recovery of Domestic Tourism Market during Public Holidays in 2020

\subsection{Arrival of full recovery in $\mathbf{2 0 2 1}$}

During the 7-day Spring Festival holiday of 2021, there were 256 million domestic trips, which surged by $15.7 \%$ year-on-year, recovered by $75.3 \%$, and the domestic tourism revenue reached 301.100 billion Yuan, up by $8.2 \%$ year on year, recovered by $58.6 \%$. Chinese urban and rural residents had a strong desire to travel during the Labor Day holiday of 2021, with 230 million domestic trips, up by $119.7 \%$ year on year, recovered by $103.2 \%$, and the total domestic tourism revenue reached 113.23 billion Yuan, up by $138.1 \%$ year on year, recovered by $77 \%$, as below in Fig.4[4]. According to Ministry of Culture and Tourism, it is predicted that domestic tourists will make 4.1 billion trips, up by $42 \%$ year on year, and the domestic tourism revenue will reach 3.3 trillion Yuan, up by $48 \%$ during the whole year of $2021[5]$.

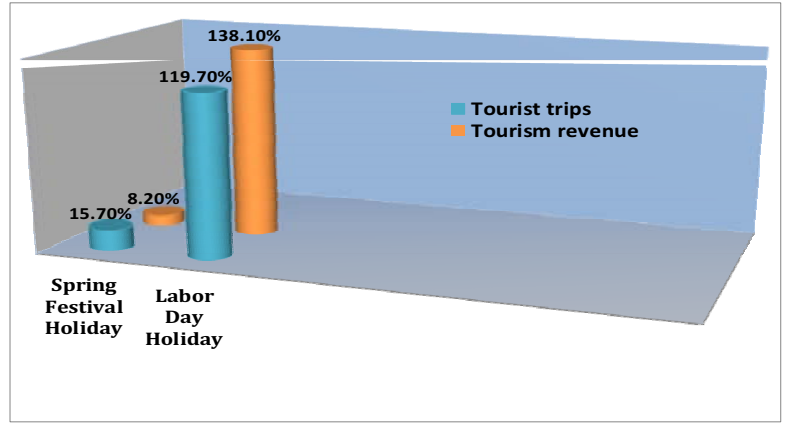

Fig.4. Growth of Domestic Tourism Market during Public Holidays in 2021

\subsection{Health being a priority}

The epidemic has enhanced, to a great extent, our awareness of health and responsibility, and more and more travelers are apt to rational and sustainable travel. Tourist destinations with high hygiene standards and anti-epidemic measures are the top choices of travelers who also pay more attention to environmental issues. At present, the personal health code that can track and record the movement of individuals has been applied in many areas and scenes. This innovative management mode can learn about the exact and timely information about epidemic situation, thus avoid excessive contacts and gatherings at airports, railway stations, shopping malls, scenic spots and other densely populated venues. Besides, many tourist spots limit the tourist flow by their booking systems and try to bring tourists a safer and better travel experience. Additionally, the tourist attractions can learn more about the travelers' demands by their bookings so as to optimize the supply and management. Booking is also an effective and important way to protect tourism resources and ensure the sustainable development of both tourist attractions and ecological environment. It can be predicted that more and more people will make their travel decisions rationally and make reservations for various tourism services before they start their trips.

\subsection{Quality leisure travel on the rise}

The inbound and outbound tourism market is still not optimistic in view of the epidemic situation abroad and the need to prevent the epidemic from rebounding at home. The travel demand of high-end consumers who originally planned to travel abroad was transmitted to the domestic market, which is accelerating the upgrade of domestic tourism products. In addition, the rise of middle-income Chinese people who would like to pay more for quality products and services, is changing tourism consumption structure. As the data shows in Fig.5[6] that mass leisure tourism revenue accounted for $36.7 \%$, quality leisure tourism revenue accounted for $30 \%$, and business tourism revenue accounted for $33.3 \%$ in 2020, and the proportion of quality leisure tourism is on the rise from 2017 to 2021 although the mass leisure tourism occupies the biggest share in present tourism market. It is certain that the quality leisure tourism 
market will have broad prospects. Tourists tend to desire high quality tourism products that can provide immersive experience and personalized services, with small group travel, tailor-made travel, free independent travel being more popular in the travel market.

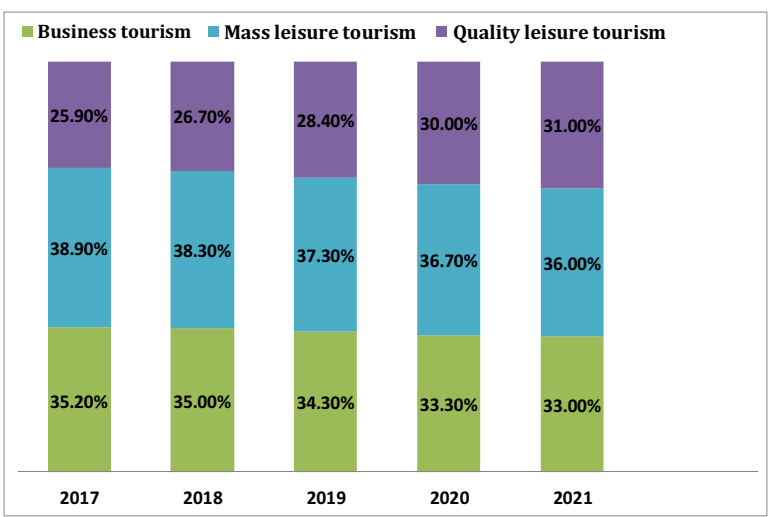

Fig.5. Statistics and Prediction on Chinese Tourism Market Share

\section{Reconstruction of tourism industry}

The tourism industry is characterized by great relevance to other industries. In recent years, the tourism industrial chain has been extending, ranging from traditional businesses such as travel agencies, scenic areas, hotels to more fields related to people's lives. Travel has become an important purchase and a kind of lifestyle. The epidemic situation would not weaken people's desire for travel, but it would change travel demands and modes. The routine epidemic prevention and control has increased the demand for contactless services and then accelerated the digitalization construction of tourism. Due to the restriction of inbound and outbound travel, the local leisure tourism market is booming, which will promote the integration of tourism and agriculture, and also benefit rural revitalization. The epidemic situation has strengthened people's concern for health, leading to a growing interest in health tourism, ecotourism, sports tourism and others. Under this background, the development of tourism industry needs to explore new ideas and integrates widely and deeply with other industries, such as education, medical care, science and technology, real estate and so on----forming an industrial cluster. Tourism enterprises needs to venture into new business and create innovative products and services to respond the changes in the tourism market.

The crossover is an inevitable trend and gives new impetus to the tourism industry. For example, rural tourism, which combines tourism with agriculture, has become an effective way to revitalize rural economy, increase farmers' income and improve rural environment. Ecotourism combines tourism with ecology to produce a "win-win" situation of economic development and ecological civilization by building forest parks, wetland parks, desert parks in poverty-stricken areas, strengthening the construction of tourism supporting facilities in nature reserves, grasslands and mountains and creating new travel forms such as ecological research travel and ecological health travel[7].

It can be predicted that the trend of industrial integration will continue to break and reconstruct the tourism industry in the future.

\section{Culture-themed scenarios of tourism consumption}

Tourists' demand shows a significant shift away from sightseeing to experience while people are paying more attention to their spiritual lives. The integration of culture and tourism is another trend in the development of the tourism industry. Tourist destinations try to create new scenarios of consumption by combining cultural activities with tourist activities. For example, Beijing Shiyuan Park received many tourists who came mainly for the 2021 Beijing Strawberry Music Festival besides sightseeing during the May Day holiday. Music fans from different parts of the country enjoyed the live performances of original musicians and bands, participated in some cultural experience activities. Such cultural activities can create new scenarios of cultural tourism and stimulate the consumer market. Moreover, tourism scenarios show a tendency from "day" to "night", with more and more tourists willing to explore the landscape of the city at night. Night tours extend the travel time, enrich the travel contents and meet the diverse consumption needs of tourists. Cultural experience has become an important part of night tours, and bookstores, tea houses and theaters are the highlights of night tour consumer market. Cultural elements and originality will become the important factors for the competition of tourism packages. Therefore, tourism enterprises need to explore the cultural symbols in planning tourist events and designing tourism products in order that create more scenarios of travel purchase. The traditional tourism products mostly feature static display and only function as sightseeing, but lack of deep experience. The introduction of cultural elements will add to the richness of the tourism products and hold a lasting attraction for people. And then, tourism enterprises can achieve a cumulative growth by the sale of cultural IP and its derivatives. Such cultural symbols as local legends and celebrities, festivals and events, folk customs, red historical stories can be integrated into the tourism products and promoted as head content of tourist destinations. For instance, some culture exhibition halls and museums can make static cultural resources closer to people by designing cartoon images, movie scenes, games, creative souvenirs, etc. In a word, the creation of culture-themed scenarios of tourism consumption can meet the tourists' need for deep experience and improve tourists' sense of satisfaction.

\section{Digital trend of tourism industry}

It seems a law that new things will be born in disasters. The COVID-19 epidemic has spawned a series of new business modes and recreations. Live-streaming, cloud technology, blockchain and other digital technology 
provide travel businesses with new thoughts and more possibilities, which alleviated the impact of the epidemic on the tourism industry, to some extent. The form of "digital travel" is not subject to business hours of tourist attractions and can create new online scenarios as well as new profit models. Here are some examples. James Liang, the co-founder of Trip.com, a online tourism business, has sold 26.91 million Yuan worth of holiday packages and hotel rooms in one hour by hosting live stream in Chinese Hanfu garments[8]. Mogao Grottoes Scenic Area has reproduced online the scene of lighting night from a thousand years ago by using mobile digital technology, made people learn about the local culture and experience the folk custom online. Another example, Pingduoduo, a Chinese online retail platform, has launched a series of live streams of "travel in China", with the first live event held in Furong town, located in western part of Hunan province, attracted 350 thousand viewers participating online.[9] Contactless service is another trend based on technology. Robots in different shapes can offer food delivery service, room service and other services in place of staff service in many restaurants, hotels and scenic areas. It's certain that the technological innovation has brought and will continue to bring more possibilities for the tourism industry and more choices for travelers.

\section{Conclusion}

People's demand for travel would not disappear, but would change due to the epidemic. Health and leisure tours are gaining momentum, indicating a shift of tourists' demand for travel. With the trend of remote work and flexible working hours, the boundary between work and leisure has become blurred, so tourism scenes and life scenes will also be integrated gradually. Given this situation, tourism enterprises need to extend their business into life fields, while some life service platforms are also getting involved in travel business, which is reconstructing the tourism industry. The cultural and artistic atmosphere in tourist destinations will have a greater influence on tourists' choice. Tourists' desire for deep experience will promote the construction of host-guest sharing scenes in tourist destinations. Last but not least, the digitalization construction in tourist destinations will be a key factor in promoting the tourism industry.

\section{References}

1. Data source: China Domestic Tourism Development Report, China Tourism Academy

2. Data source: China Domestic Tourism Development Report, China Tourism Academy

3. Data source: China Domestic Tourism Development Report, China Tourism Academy

4. Data source: China Domestic Tourism Development Report, China Tourism Academy
5. It was predicted by Data Center, Ministry of Culture and Tourism according to the big data from communication operators.

6. Data source: A Research Report on Market Outlook and Investment Opportunities of China's Tourism industry, Askci Corporation, http://www.askci.com

7. Pei Li, Ideal and Rationality of Revitalizing Tourism in the Post-epidemic Era, E3S Web of Conferences235,02050(2021), https://doi.org/10.1051/e3sconf/202123502050

8. Data source: http://www.TechWeb.com.cn 2020-0403

9. Data source: http://www.REDNET.CN, 2020-04-28 